УДК 006.91

DOI: https://doi.org/10.36910/6775-2313-5352-2019-14-21

Сасов О.О., К.т.н., Авер'янов В.С., к.т.н., Шматко Д.3., к.т.н..

Дніпровський державний технічний університет

\title{
УПРАВЛІННЯ РЕЖИМНИМИ ПАРАМЕТРАМИ ТА ПРОЦЕСОМ ЗНОШУВАННЯ РІЖУЧОГО ІНСТРУМЕНТУ ПРИ РОЗРІЗАННІ НАВПІЛ ЗНОШЕНИХ АВТОМОБІЛЬНИХ ШИН
}

В результаті проведеної роботи визначені закономірності зміни режсимних параметрів під час розрізання навпіл зношених автомобільних шин 195/65R15 діаметром 662 мм ріжучим інструментом зі сплаву Р6М5, які забезпечують збільшення стійкості ріжучого інструменту до зносу, собівартість близької до мінімальної та максимальної продуктивності. В якості керуємого процесу розглядається процес зношування задніх поверхонь ріжучого інструменту. Встановлено, що управлінням швидкістю різання та подачею ріжучого інструменту дозволяе змінити швидкість прочесу зносу ріжучого інструменту, тобто до збільшення часу роботи ріжучого інструменту. Розраховані та побудовані криві зносу ріжучого інструменту зі сплаву Р6М5 та швидкості його зносу у відповідності з управлінням режимними параметрами при розрізанні навпіл зношеної автомобільної шини. Вирішення проблеми управління режимними параметрами сприяє підвищенню ефективності механічної обробки різанням та доповнює математичне та інформаційне забезпечення систем автоматизованого проектування технологічних процесів (САПР ТП) які використовуються під час утилізаиіі зношених автомобільних шин

Ключові слова: режимні параметри, ивидкість різання, подача ріжучого інструменту, сили різання, пневматична шина, утилізація шин, швидкість зносу, якість управління.

Постановка проблеми. Загальна проблема моделювання, оптимізації процесу різання та управління їм розглянуто в ряді досліджень, наприклад у загальній формі в роботі [1]. В монографії [2] приведені результати досліджень які направлені на конкретизацію загальної проблеми з застосуванням до умов одноінструментної однолезвійної однопозиційної обробки. Так процес різання та зношування інструменту прийнято об'єктом управління та представлено як керований детермінований процес з відомою метою управління досягнення якої можливе завдяки закономірної зміни в часі режимних параметрів. Процес різання зовнішні проявляється як процес зношування ріжучого інструменту, а проблема забезпечення управління режимними параметрами зводиться до математичного опису функції швидкості зношування інструменту, технологічних обмежень, функціоналів якості управління та вибору і адаптації математичних методів оптимізації. Вирішення проблеми управління режимними параметрами сприяє підвищенню ефективності механічної обробки різанням та доповнює математичне та інформаційне забезпечення систем автоматизованого проектування технологічних процесів (САПР ТП) які використовуються під час утилізації зношених автомобільних шин. Задача пошуку функції, що характеризує швидкість зношування ріжучого інструменту від режимних ті інших параметрів для складання співвідношень, що характеризують стан процесу зносу $\epsilon$ одною з головних задач по формуванню автоматизованих систем технологічної підготовки виробництва (AC ТПВ), САМ-систем, CASE-систем для розробки та супроводу програмного забезпечення САПР.

Аналіз основних досліджень і публікацій. Аналіз літературних джерел показав відсутність публікацій, які безпосередньо відносяться до проблеми управління режимними параметрами процесу різання зношених пневматичних шин під час їх утилізації, натомість існує низка робіт, які стосуються проблема моделювання, оптимізації процесу різання зношених автомобільних шин. Створенням математичної моделі формування сил різання при розрізанні зношених пневматичних шин навпіл займалися - Сасов О.О., Коробочка О.M., Коржавін Ю.А., Авер'янов В.С.[3]. Математичним моделюванням процесів різання матеріалів присвячені роботи $[4,5,6]$ за результатами яких була запропонована загальна послідовність розрахунку швидкості зносу ріжучого інструменту при різанні металів. Теоретичні методи розрахунку сил різання для різних видів обробки різанням в узагальненому вигляді знайшла відображення в роботі [4] де проведені експериментальні дослідження підтверджують нелінійний характер впливу зносу ріжучого інструменту на сили різання. Методами оптимізації режимних параметрів лезвійної обробки металів займався С.В. Грубий в роботі [7]. Значною

(С Сасов О.О., к.т.н., Авер'янов В.С., к.т.н., Шматко Д.З., к.т.н.. 
проблемою є складність математичного моделювання процесу різання шин, оскільки існує велика кількість взаємовпливаючих параметрів ріжучого інструменту і процесу обробки, а також різноманітні властивості шини (пола форма, велика механічна зносостійкість, пружні властивості матеріалу, наявність металічного корду та текстилевих волокон, хімічний склад гуми, тощо), що зумовлює труднощі та нестабільність лезвійної обробки. Саме цим можна пояснити невелику кількість публікації присвячених цьому питанню, та неоднозначність їх висновків.

Мета роботи. Визначити закономірності зміни режимних параметрів під час розрізання навпіл зношених автомобільних шин, які забезпечують відповідну зміну швидкості зношування ріжучого інструменту.

Матеріали досліджень. Рішення загальних задач управління режимними параметрами розрізання зношених шин навпіл запропоновано знаходити на основі загальних положень математичної теорії оптимальних процесів та теорії управління [8,9]. В якості керуємого процесу розглядається процес зношування задніх поверхонь ріжучого інструменту. Основне завдання оптимального управління - вибір способу управління зі всіх можливих, для якого інтегральний функціонал якості управління приймає найменше значення при одночасному збільшенні фазової координати (лінійного зносу по задній поверхні) від $\mathrm{h}_{z 0}$ до $\mathrm{h}_{\text {zmax. }}$

Сформульовану постановку задачі можна представити системою нелінійних диференціальних рівнянь:

- швидкість зношування ріжучого інструменту

$$
f_{1}=\frac{d x_{1}}{d \tau}=\frac{d h_{z}}{d \tau}=\operatorname{Int}\left(h_{z n}, v_{n}, s_{n}, \tau\right)_{\mid t_{n}=c o n s t}
$$

- інтегральний функціонал якості управління

$$
x_{0}=\int_{0}^{T_{v}} f_{0}\left(h_{z n}, v_{n}, s_{n}, T_{v}\right) d \tau=\sum_{j=1}^{N_{v}} C_{p j} t_{0 j} \rightarrow \min
$$

де $\mathrm{h}_{z \mathrm{n}}-$ лінійний знос по задній поверхні ріжучого інструменту;

$\mathrm{V}_{\mathrm{n}}$ - швидкість різання;

$\mathrm{S}_{\mathrm{n}}$ - подача ріжучого інструменту;

Int - функція зношування ріжучого інструменту;

$\mathrm{T}_{\mathrm{v}}$ - заданий час обробки;

$\mathrm{N}_{\mathrm{v}}$ - число точок управління;

$\mathrm{C}_{\mathrm{pj}}$ - змінна частина собівартості розрізання шини навпіл;

$\mathrm{t}_{\text {ouj }}$ - крок за часом обробки, який визначає число точок управління.

Функція Гамільтона-Понтрягіна пов'язує цільову функцію (2) та швидкість зношування ріжучого інструменту (1) через парні змінні $\Psi_{0} \Psi_{1}$ :

$$
H=\Psi_{0 j} f_{0}\left(h_{z n}, v_{n}, s_{n}, T_{v}\right)+\Psi_{1} f_{1}\left(h_{z n}, v_{n}, s_{n}, \tau\right)
$$

У свою чергу, зв'язок парних змінних за точками управління визначена системою диференціальних рівнянь

$$
\begin{aligned}
& \frac{d \Psi_{0 j}}{d h_{z}}=-\frac{1}{f_{0}}\left(\Psi_{0 j} \frac{d f_{0}}{d h_{z}}+\Psi_{1 j} \frac{d f_{1}}{d h_{z}}\right) ; \\
& \frac{d \Psi_{1 j}}{d h_{z}}=-\frac{1}{f_{1}}\left(\Psi_{0 j} \frac{d f_{0}}{d h_{z}}+\Psi_{1 j} \frac{d f_{1}}{d h_{z}}\right),
\end{aligned}
$$

3 початковими значеннями $\Psi_{00}\left(\mathrm{~h}_{\mathrm{z0}}\right)=\Psi_{0 \mathrm{n}}, \Psi_{10}\left(\mathrm{~h}_{\mathrm{z} 0}\right)=\Psi_{1 \mathrm{n}}$.

Частні похідні, що входять до рівняння (4), визначені чисельним диференціюванням другого порядку точності

$$
\begin{aligned}
\frac{d f_{0}}{d h_{z}} & =\frac{C_{p j}\left(v_{o p t j}, h_{z n}+h\right)-C_{p j}\left(v_{o p t j}, h_{z n}-h\right)}{2 h} ; \\
\frac{d f_{1}}{d h_{z}} & =\frac{\operatorname{Int}\left(v_{o p t j}, h_{z n}+h\right)-\operatorname{int}\left(v_{o p t j}, h_{z n}-h\right)}{2 h},
\end{aligned}
$$

де $\mathrm{h}$ - дискретне значення зносу, прийняте в процедурах чисельного диференціювання. 
Рішення диференційних рівнянь (4) знайдено в рамках постановки загальної задачі Коші на кінцевій більшості точок управління

$$
\begin{aligned}
& h_{z n}=h_{z 0}+j \Delta_{h}, j=0,1,2, \ldots ; \\
& h_{z 0} \leq h_{z n} \leq h_{z \max } .
\end{aligned}
$$

Використано метод Рунге-Кутта четвертого порядку точності, де для находження значень змінних чисельним методом в $(\mathrm{j}+1)$-й точці управління використані значення в $\mathrm{j}$-й точці.

Рівняння (4) представлено у формі

$$
\begin{aligned}
& \frac{d \Psi_{1 j}}{d h_{z}}=f_{\Psi 1}\left(h_{z n}, \Psi_{1 j}, \Psi_{0 j}\right) ; \\
& \frac{d \Psi_{0 j}}{d h_{z}}=f_{\Psi 0}\left(h_{z n}, \Psi_{1 j}, \Psi_{0 j}\right) .
\end{aligned}
$$

Значення змінної для наступної точки управління визначено в загальному вигляді як

$$
\Psi_{1(0), j+1}=\Psi_{1(0), j}+\frac{1}{6}\left(k_{1}+2 k_{2}+2 k_{3}+k_{4}\right),
$$

де значення коефіцієнтів, наприклад для визначення змінної $\Psi_{1, j+1}$, складають:

$$
\begin{aligned}
& k_{1}=h_{r} f_{\Psi 1}\left(h_{z n}, \Psi_{1 j}, \Psi_{0 j}\right) ; \\
& k_{2}=h_{r} f_{\Psi 1}\left(h_{z n}+\frac{h_{r}}{2}, \Psi_{1 j}+\frac{k_{1}}{2}, \Psi_{0 j}\right) ; \\
& k_{3}=h_{r} f_{\Psi 1}\left(h_{z n}+\frac{h_{r}}{2}, \Psi_{1 j}+\frac{k_{2}}{2}, \Psi_{0 j}\right) ; \\
& k_{4}=h_{r} f_{\Psi 1}\left(h_{z n}+h_{r}, \Psi_{1 j}+k_{3}, \Psi_{0 j}\right),
\end{aligned}
$$

де $\mathrm{h}_{\mathrm{r}}$ - дискретне значення зносу ріжучого інструменту у процедурах Рунге-Кутта.

Аналогічним чином визначили значення змінної $\Psi_{0, j+1}$.

Розрахунок значень швидкості різання та подачі в кожній точці управління виконано у відповідності з принципом максимуму Понтрягіна: $\mathrm{H} \rightarrow \max$. У якості робочого алгоритму прийнята мінімізація функції - Н:

$$
f_{u}=-H \rightarrow \min ,
$$

де $\mathrm{H}$ - функція Гамільтона-Понтрягіна (3).

Мінімізація функції (10) виконано методом градієнтного спуску зі змінним кроком, який передбачує ітерацію з режимними параметрами, що управляються в кожній точці управління:

$$
\begin{aligned}
& v_{n, i+1}=v_{n i}-\alpha_{v i} \frac{d f_{u}\left(v_{n i}, s_{n i}\right)}{d v} ; \\
& s_{n, i+1}=s_{n i}-\alpha_{s i} \frac{d f_{u}\left(v_{n i}, s_{n i}\right)}{d s}
\end{aligned}
$$

Градієнти функції за напрямами визначені методом чисельного диференціювання другого порядку точності:

$$
\begin{aligned}
& \frac{d f_{u}}{d v} \mid v_{n i}, s_{n i}=\frac{f_{u}\left(v_{n i}+d v, s_{n i}\right)-f_{u}\left(v_{n i}-d v, s_{n i}\right)}{2 d v} ; \\
& \frac{d f_{u}}{d s} \mid v_{n i}, s_{n i}=\frac{f_{u}\left(v_{n i}, s_{n i}+d s\right)-f_{u}\left(v_{n i}, s_{n i}-d s\right)}{2 d s},
\end{aligned}
$$

де dv,ds - дискретні значення швидкості та подачі у процедурах чисельного диференціювання.

Умови визначення оптимальних значень швидкості та подачі в кожній точці управління прийнято у вигляді:

3 крайовими умовами

$$
\begin{gathered}
v_{o p t j}=v_{n, i+1} ; s_{o p t j}=s_{n, i+1} ; \\
f_{u}\left(v_{n i}, s_{n i}\right)-f_{u}\left(v_{n, i+1}, s_{n, i+1}\right) \leq \varepsilon ; \\
v_{\min } \leq v_{n, i+1} \leq v_{\max } ; s_{\min } \leq s_{n, i+1} \leq s_{\max }
\end{gathered}
$$

(ㄱ Сасов О.О., к.т.н., Авер'янов В.С., к.т.н., Шматко Д.З., к.т.н.. 


$$
\begin{gathered}
h_{z n}(0)=h_{z 0} ; \Psi(0)=\left(\Psi_{0 n}, \Psi_{1 n}\right) ; \\
h_{z n}\left(T_{v}\right)=h_{z n}(\tau) \leq h_{z \max } ; \Psi\left(T_{v}\right)=\left[\Psi_{0}(\tau), \Psi_{1}(\tau)\right],
\end{gathered}
$$

де $\varepsilon$ - мала величина, а ліміти зміни швидкості та подачі $\mathrm{v}_{\min }, \mathrm{v}_{\max }, \mathrm{s}_{\min }$, $\mathrm{s}_{\max }$ обмежені відповідними діапазонами зміни цих параметрів у рівнянні швидкості зносу ріжучого інструменту.

Встановлено, що вибір початкового значення парної змінної $\Psi_{1 \mathrm{n}}$ дозволяє змінити швидкість процесу зносу ріжучого інструменту, при цьому зменшення цього значення призводить до зменшення швидкості зношування, тобто до збільшення часу роботи ріжучого інструменту[2]. Підбиранням початкового значення змінної $\Psi_{\ln }$ можна досягти того, що для заданого часу обробки $\mathrm{T}_{\mathrm{v}}$ знос досягне максимально допустимого значення $\mathrm{h}_{\text {zmax }}$.

Параметри управління режимними параметрами розраховані для одноінструментного розрізання зношеної автомобільної шини 195/65R15 діаметром 662 мм ріжучим інструментом зі сплаву Р6М5 з геометричними параметрами: передній кут $\gamma=20^{\circ}$, кут при вершині $\varepsilon=53^{\circ}$, задній кут $\alpha=68^{\circ}$. Використані поліноміальні рівняння отримані за експериментальними даними:

- вертикальної складової сили різання $\mathrm{P}_{z}$ для умов розрізання пневматичних шин навпіл твердосплавними різцями (12) [3];

- швидкості зносу Int твердосплавних різців при обробці стальних заготівок (1.22) [2].

Сили різання для умов розрізання зношених автомобільних шин розраховані по рівнянням приведеним в роботі [3].

Графіки зміни швидкості різання та подачі для трьох варіантів заданого часу розрізання $\mathrm{T}_{\mathrm{v}}=1 ; 2 ; 3$ хвилин приведені на рисунку 1 та 2 відповідно

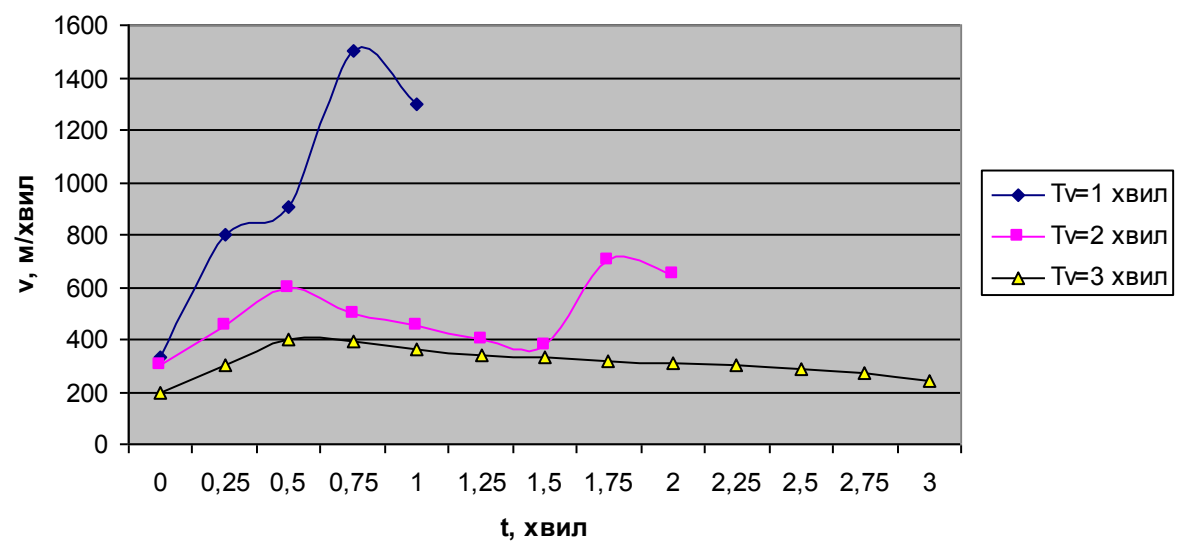

Рис. 1. Управління швидкістю різання v зношеної автомобільної шини 195/65R15 діаметром 662 мм ріжучим інструментом зі сплаву Р6М5 з геометричними параметрами: передній кут $\gamma=20^{\circ}$, кут при вершині $\varepsilon=53^{\circ}$, задній кут $\alpha=68^{\circ}$ для заданого часу розрізання

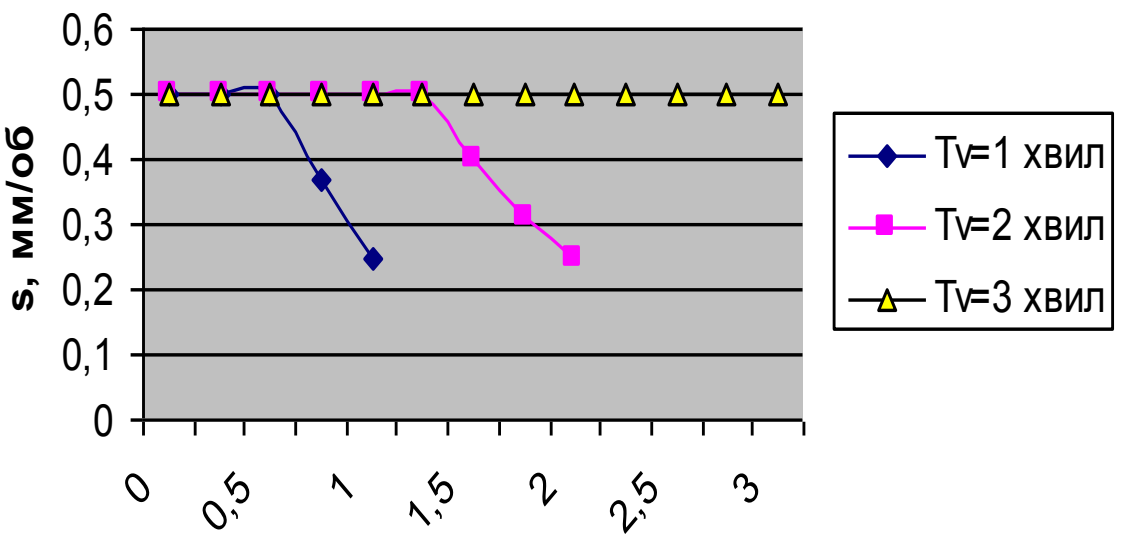

\section{t,хвил}

Рис. 2. Управління подачею різання s зношеної автомобільної шини 195/65R15 діаметром 662 мм ріжучим інструментом зі сплаву Р6М5 з геометричними параметрами: передній кут $\gamma=20^{\circ}$, кут при вершині $\varepsilon=53^{\circ}$, задній кут $\alpha=68^{\circ}$ для заданого часу розрізання

(С Сасов О.О., к.т.н., Авер'янов В.С., к.т.н., Шматко Д.3., к.т.н.. 
Розрахункові криві зносу ріжучого інструменту зі сплаву Р6М5 та швидкості його зносу у відповідності з управлінням режимними параметрами (рис.1 та 2) при розрізанні навпіл зношеної автомобільної шини 195/65R15 приведені на рисунках 3 та 4 відповідно.

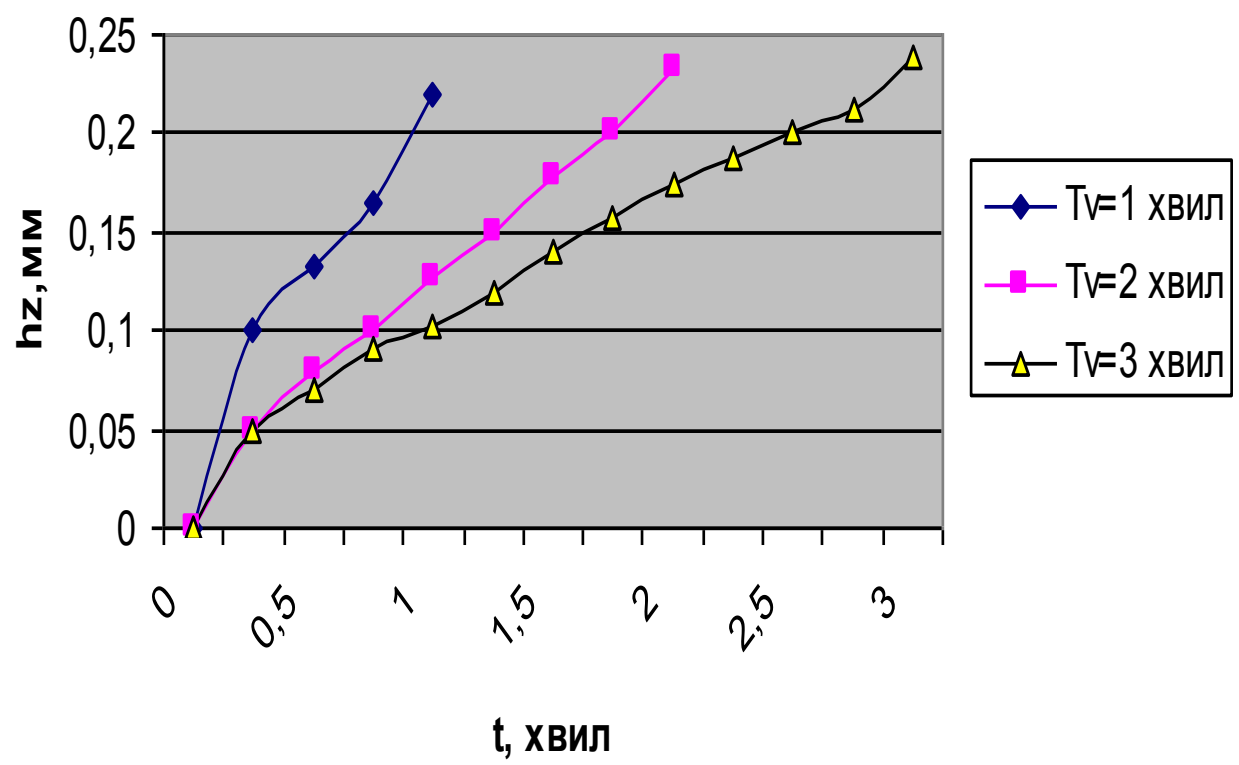

Рис. 3. Розрахункові криві зносу $\mathrm{h}_{z}$ ріжучого інструменту зі сплаву Р6М5 у відповідності з управлінням режимними параметрами при розрізанні навпіл зношеної автомобільної шини $195 / 65 \mathrm{R} 15$

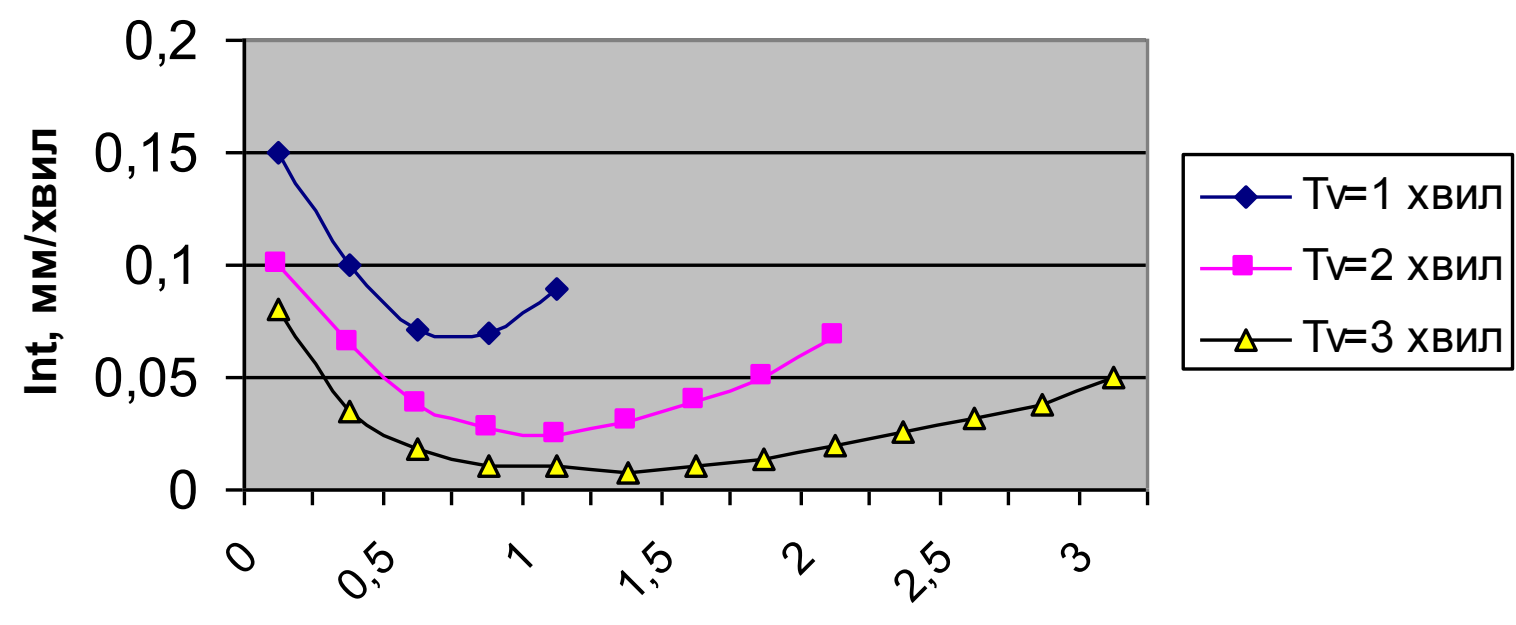

t, хвил

Рис. 4. Розрахункові криві швидкості зносу Int ріжучого інструменту зі сплаву Р6М5 у відповідності з управлінням режимними параметрами при розрізанні навпіл зношеної автомобільної шини 195/65R15

Графіки, що характеризують зміну режимних параметрів від часу (рис.1 та рис. 2) мають змінний характер, як і швидкість зносу інструменту (рис.4). На кривих зносу фактично відсутні ділянки 3 постійною швидкістю зносу ріжучого інструменту. Такий процес зносу характерний для інструменту, який оснащений змінними багатогранними пластинами з твердих сплавів.

Висновки. Встановлено, що зміна швидкості та подачі ріжучого інструменту впливає на його швидкість зносу. В результаті проведеної роботи визначені закономірності зміни режимних параметрів під час розрізання навпіл зношених автомобільних шин 195/65R15 діаметром 662 мм ріжучим інструментом зі сплаву P6M5 з геометричними параметрами: передній кут $\gamma=20^{\circ}$, кут при вершині $\varepsilon=53^{\circ}$, задній кут $\alpha=68^{\circ}$. Розраховані режимні параметри

(С Сасов О.О., к.т.н., Авер'янов В.С., к.т.Н., Шматко Д.З., к.т.н.. 
які забезпечують збільшення стійкості ріжучого інструменту до зносу, собівартість близької до мінімальної та максимальної продуктивності.

\section{Інформаційні джерела}

1. Петрушин С.И., Грубый С.В. Обработка чугунок и сталей сборными резцами со сменными многогранними пластинами. Томск: ТПУ, 2000. 156 с.

2. Оптимизация процесса механической обработки и управления режимными параметрами / С.В. Грубый. - Москва: МГТУ им. Н.Э. Баумана, 2014. - 149 с.

3. Sasov A. Study of energy efficiency of the processes of mechanical destruction of worn automobile tires. A.Sasov, A. Korobochka, V. Averyanov, Iu. Korzhavin.// Eastern European Journal of Enterprise Technologies. Engineering technological systems. Kharkiv. 6/1 (90) 2017. - P.51-60..

4. Розенберг Ю.А. Резания материалов: учеб. для техн.. вузов. Курган: ОАО «Полиграф. Комбінат «Зауралье», 2007. 294 с.

5. Верещак А.С., Кушнер В.С. Резания материалов: учеб. М.: Высш. Шк.., 2009. 535 с.

6. Грубый С.В. Моделирование процесса резания твердосплавними и алмазними резцами: учеб. пособие. М.: МГТУ им. Н.Э. Баумана, 2010. 107 с.

7. Грубый С.В. Методы оптимизации режимних параметров лезвийной обработки: учеб. пособие. М.: МГТУ им. Н.Э. Баумана, 2008. 96 с.

8. Ванько В.И., Ермошина О.В., Кувыркин Г.Н. Вариационное исчесление и оптимальное управление / под ред. В.С. Зарубина, А.П. Крищенко. . М.: МГТУ им. Н.Э. Баумана, 1999. 487 с.

9. Математическая теория оптимальных процессов /Л.С. Понтрягин, В.Г. Болтянский, Р.В. Гамкрелидзе, Е.Ф. Мищенко. М.: Наука, 1983. 392 с.

УДК 006.91

Сасов А.А., к.т.Н., Аверьянов В.С., к.т.н., Шматко Д.З., к.т.н..

Днепровский государственный технический университет

\section{УПРАВЛЕНИЕ РЕЖИМНЫМИ ПАРАМЕТРАМИ И ПРОЦЕССОМ ИЗНАШИВАНИЯ РЕЖУЩЕГО ИНСТРУМЕНТА ПРИ РАЗРЕЗАНИИ ПОПОЛАМ ИЗНОШЕННЫХ АВТОМОБИЛЬНЫХ ШИН}

В результате проведенной работы определены закономерности изменения режсиных параметров при разрезании пополам изношенных автомобильных иин 195 / $65 R 15$ диаметром 662 мм режущим инструментом из сплава Р6М5, которые обеспечивают увеличение стойкости режущего инструмента к износу, себестоимость близкой к минимальной $и$ максимальную производительность. В качестве управляемого процесса рассматривается процесс износа задних поверхностей режущего инструмента. Установлено, что управлением скоростью резания и подачей режущего инструмента позволяет изменить скорость процесса износа режущего инструмента, то есть к увеличению времени работы режущего инструмента. Рассчитаны кривые износа режущего инструмента из сплава Р6М5 и скорости его износа в соответствии с управлением режимными параметрами при разрезании пополам изноменной автомобильной шины. Решение проблемы управления режимными параметрами способствует повышению эффективности механической обработки резанием и дополняет математическое $и$ информационное обеспечение систем автоматизированного проектирования технологических процессов (САПР ТП) которые используются при утилизачии изношенных автомобильных шин

Ключевые слова: режимные параметры, скорость резания, подача режущего инструмента, силь резания, пневматическая шина, утилизащия шин, скорость износа, качество управления.

UDC 006.91

Sasov A.A., c.t.s., Averianov V.S., c.t.s., Shmatko D.Z. c.t.s..

Dneprovskiy State Technical University, Kamenskoe, Ukraine

MANAGEMENT OF MODE PARAMETERS AND THE PROCESS OF WEARING THE CUTTING TOOL WHEN CUTTING THE AMOUNT OF WRONTED AUTOMOBILE TIRES

(С Сасов О.О., к.т.н., Авер'янов В.С., к.т.н., Шматко Д.3., к.т.н.. 
As a result of this work, regularities of changes in operating parameters are determined when cutting worn out car tires 195 / 65R15 with a diameter of $662 \mathrm{~mm}$ with a cutting tool made of R6M5 alloy, which provide an increase in the wear resistance of the cutting tool, cost value close to the minimum and maximum performance. The process of wear of the back surfaces of the cutting tool is considered as a controlled process. It has been established that by controlling the cutting speed and the feed of the cutting tool, it is possible to change the speed of the wear process of the cutting tool, that is, to increase the operating time of the cutting tool. Calculated wear curves of the cutting tool from alloy R6M5 and its wear rate in accordance with the control of operating parameters when cutting a worn out car tire in half. Solving the problem of managing regime parameters improves the efficiency of mechanical machining and complements the mathematical and informational support of computer-aided design of technological processes used for recycling used tires

Key words: regime parameters, cutting speed, cutting tool feed, cutting forces, pneumatic tire, tire utilization, wear rate, control quality. 